\title{
RELATING PARASITE COMMUNITIES TO HOST ENVIRONMENTAL CONDITIONS USING PHYLOGENETIC TOOLS
}

\author{
CABARET J.*
}

\section{Summary:}

There are many tools available for analysing parasite communities, either based on the proportions or presence/absence of species. These analyses rely on phylogenetic distances, and analyses of actual characters (e.g. species). The phylogenetic analysis (Wagner parsimony) was compared to a cluster analysis (UPGMA) and correspondence analyses of two real helminth communities in sheep lone farm and with repeated sampling along time) or goats (several farms, each sampled once). The cladograms obtained using Wagner parsimony provided a clearer structuring of the helminth communities than classical analyses. The homogeneous groups of parasite communities on goat farms were significantly related (Fisher' exact test) to the environmental characteristics. The evolution along time pattern of change in the sheep infection of sheep was not the same for in all the animals, and two groups of communities could be distinguished in the last lamb cohorts. Phylogenetic analyses provide an effective performing tool to for interpreting the change in evolution of helminth communities with environmental conditions.

KEY WORDS : community, parasite, environment, phylogeny
Résumé : UTILISATION DES INSTRUMENTS DE LA PHYLOGÉNIE POUR COMPARER DES COMMUNAUTÉS DE PARASITES ET DES ENVIRONNEMENTS Les outils pour analyser les communautés de parasite sont nombreux, et ils se fondent sur des données quantitatives ou de présence/absence. Ces analyses portent sur des distances, et les analyses phylogénétiques sur des caractères (espèce présente ou non). L'analyse phylogénétique (parcimonie de Wagner) a été comparée aux analyses hiérarchiques ascendantes et de correspondance sur deux ensembles de données. Le premier porte sur des helminthes d'ovins (une ferme suivie sur plusieurs cohortes) ou de chèvres (plusieurs fermes étudiées au même moment). Les cladogrammes obtenus avec la parcimonie de Wagner donnent une meilleur structuration des communautés d'helminthes que les analyses classiques. Les groupes homogènes de communautés d'helminthes dans les fermes sont significativement reliés (test exact de Fisher) aux caractéristiques environnementales des fermes. L'évolution au cours du temps des communautés d'helminthes d'ovins n'était pas semblable et deux groupes de communautés étaient rencontrés dans la dernière cohorte. L'analyse phylogénétique est un bon intrument pour interpreter l'évolution des communautés de parasites en relation avec les conditions environnementales dans lesquelles les hôtes sont hébergés

MOTS CLÉS : communauté, parasite, environnement, phylogénie.

commonly used to analyse such data. These phenetic analyses are based on the distance matrix and not directly on characters. Conversely, in phylogenetic methods, each character is polarised (in this case the species presence or absence of a species) and is used directly in the analysis. Few studies are available about the use of phylogenetic methods in ecology, although comparisons of cladistic analysis and principal component analysis were in favour of the former (Lambshead \& Paterson, 1986; Bellan-Santini, Dauvin \& Bellan, 1994). Only one application has been attempted on using real data in parasite community ecology data (Brooks, 1985): a cladogram of the river systems in south America was based on the occurrence of sting ray parasites.

We will use three parasitological data sets to describe our method. The first set is imaginary, and corresponds to the main types of binary data. The second set has been taken from Cabaret \& Gasnier (1994); it concerns parasitic digestive-tract nematodes of dairy-goats in the centerwest of France and provides a snapshot the picture of the distribution of the infection at one moment

* INRA, BASE, 37380 Nouzilly, France

Tel.: 33 (0) 247427768 - Fax : 33 (0) 247427774 .

E-mail: cabaret@tours.inra.fr 
of during the year of the infection; these data have already been previously analysed. The third data set concerns consists of meat lambs for slaughter that were studied for during nearly two years, so that the infection of five cohorts can be studied; the data had also been previously analysed previously using a general linear model (Giudici et al, 1999). The aim of this paper is to describe the use of a phylogenetic method based on the putative historical evolution to compare communities and to relate them to the host environment. We will compare our phylogenetic method in comparison with classical analytic methods for binary data.

\section{MATERIALS AND METHODS}

\section{DATA}

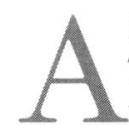

imaginary data set was constructed (Table I). The original data were polythetic in the sense used by Beckner (1959). Suppose that we have a group of farms known as $\mathrm{K}$ with an aggregation, $\mathrm{G}$, of species $1,2,3 \ldots$, such that: $i$ ) each of the farms in $\mathrm{K}$ has a large number of the species in $\mathrm{G}, i$ i) each species in $G$ is present on a large number of the $\mathrm{K}$ farms, iii) no species is present on all the $\mathrm{K}$ farms. If conditions $i$ ) and $i$ ) are fulfilled, the data are partially polythetic (all cases from a to p). If all three conditions are fulfilled, the data are fully polythetic (see farms a to $\mathrm{g}$, and species 1 to 7 in Table I). The fully polythetic group of farms (a to g) has an aggregate of the first seven species: each farm from a to $g$ has a large number of these species (six out of the seven), but no species is found on all the farms. If a larger number of species is considered (16), only farms from a to $g$ are polythetic, since a large number of the available species are found on each farm (1 to 16), each species is found on a large number of farms, and several species are found on all the farms.

The presence/absence of gastrointestinal nematode species when goats from 16 farms in the Centre-West region of France were necropsied in autumn are shown in Table II. For each farm, data from two goats were pooled. Nematodes were identified to species level. The following management factors (Table III) were recorded since they play a role in: $a$ ) increasing the number of species (number of goats introduced when the farm was first constituted, number of farms from which they originated, whether any goats had been bought after the farm had been constituted, use of permanent pastures) (Gasnier et al, 1997), and b) in decreasing the number of nematode species (late turnout, no number of anthelmintic treatments: Silvestre et $a l, 2000)$. Some of the data were quantitative and were transformed into binary data, for example the number of treatments (less than or equal to one $=0$ and more than one per year $=1$ ), of the time since the farm was setup (less than thre years $=0$, three years or more $=$ 1). This transformation was necessary since we wanted

\begin{tabular}{|c|c|c|c|c|c|c|c|c|c|c|c|c|c|c|c|c|}
\hline \multirow[b]{2}{*}{ Farm } & \multicolumn{16}{|c|}{ Species } \\
\hline & 1 & 2 & 3 & 4 & 5 & 6 & 7 & 8 & 9 & 10 & 11 & 12 & 13 & 14 & 15 & 16 \\
\hline Outgroup & 0 & $O$ & $O$ & $O$ & o & $O$ & O & $O$ & $O$ & $O$ & $O$ & 0 & 0 & $O$ & $O$ & 0 \\
\hline a & 0 & 1 & 1 & 1 & 1 & 1 & 1 & 1 & 1 & 1 & 1 & 1 & 1 & 1 & 1 & 1 \\
\hline b & 1 & 0 & 1 & 1 & 1 & 1 & 1 & 1 & 1 & 1 & 1 & 1 & 1 & 1 & 1 & 1 \\
\hline c & 1 & 1 & 0 & 1 & 1 & 1 & 1 & 1 & 1 & 1 & 1 & 1 & 1 & 1 & 1 & 1 \\
\hline $\mathrm{d}$ & 1 & 1 & 1 & 0 & 1 & 1 & 1 & 1 & 1 & 1 & 1 & 1 & 1 & 1 & 1 & 1 \\
\hline e & 1 & 1 & 1 & 1 & 0 & 1 & 1 & 1 & 1 & 1 & 1 & 1 & 1 & 1 & 1 & 1 \\
\hline $\mathrm{f}$ & 1 & 1 & 1 & 1 & 1 & 0 & 1 & 1 & 1 & 1 & 1 & 1 & 1 & 1 & 1 & 1 \\
\hline $\mathrm{g}$ & 1 & 1 & 1 & 1 & 1 & 1 & 0 & 1 & 1 & 1 & 1 & 1 & 1 & 1 & 1 & 1 \\
\hline $\mathrm{h}$ & 1 & 1 & 0 & 0 & 0 & 0 & 0 & 0 & 0 & 1 & 1 & 1 & 1 & 1 & 1 & 1 \\
\hline $\mathrm{i}$ & 1 & 1 & 1 & 0 & 0 & 0 & 0 & 0 & 0 & 0 & 1 & 1 & 1 & 1 & 1 & 1 \\
\hline i & 1 & 1 & 1 & 1 & 0 & 0 & 0 & 0 & 0 & 0 & 0 & 1 & 1 & 1 & 1 & 1 \\
\hline $\mathrm{k}$ & 1 & 1 & 1 & 1 & 1 & 0 & 0 & 0 & 0 & 0 & 0 & 0 & 1 & 1 & 1 & 1 \\
\hline 1 & 1 & 1 & 1 & 1 & 1 & 1 & 0 & 0 & 0 & 0 & 0 & 0 & 0 & 1 & 1 & 1 \\
\hline $\mathrm{m}$ & 1 & 1 & 1 & 1 & 1 & 1 & 1 & 1 & 0 & 0 & 0 & 0 & 0 & 1 & 1 & 1 \\
\hline $\mathrm{n}$ & 1 & 1 & 1 & 1 & 1 & 1 & 1 & 1 & 0 & 0 & 0 & 0 & 1 & 0 & 1 & 1 \\
\hline o & 1 & 1 & 1 & 1 & 1 & 1 & 1 & 1 & 0 & 0 & 0 & 0 & 1 & 1 & 0 & 1 \\
\hline $\mathrm{p}$ & 1 & 1 & 1 & 1 & 1 & 1 & 1 & 1 & 1 & 1 & 0 & 0 & 1 & 1 & 1 & 0 \\
\hline
\end{tabular}

Outgroup farm in italics: absence of any species (no species).

Pale-shading (a to g): 16 species, nine species in common; polythetic structure of species 1 to 7 .

Unshaded (h to k): nine species, including six species in common.

Dark-shading ( 1 to $\mathrm{p}$ ): nine to 13 species, including six species in common.

Table I. - Imaginary data set of parasite species (0: absent, 1: present) in hosts from 16 farms. 


\section{Nematodes species}

\begin{tabular}{|c|c|c|c|c|c|c|c|c|c|c|c|c|c|c|c|c|}
\hline \multirow[b]{2}{*}{ Farm } & \\
\hline & tc & tco & to & OV & $\mathrm{tt}$ & so & OO & hc & ta & $\mathrm{tv}$ & $\mathrm{nf}$ & ns & $\mathrm{sp}$ & $\mathrm{COO}$ & cap & cho \\
\hline Aug & 1 & 1 & 0 & 0 & 0 & 0 & 0 & 0 & 0 & 0 & 0 & 0 & 0 & 0 & 0 & 0 \\
\hline Bau & 1 & 1 & 1 & 0 & 0 & 0 & 0 & 0 & 0 & 0 & 0 & 0 & 0 & 0 & 0 & 0 \\
\hline Ber & 1 & 1 & 1 & 1 & 1 & 1 & 0 & 0 & 0 & 0 & 0 & 0 & 0 & 0 & 0 & 0 \\
\hline Bod & 1 & 1 & 0 & 0 & 1 & 0 & 0 & 0 & 0 & 0 & 0 & 0 & 0 & 0 & 0 & 0 \\
\hline Cas & 1 & 1 & 0 & 0 & 1 & 1 & 1 & 1 & 0 & 0 & 0 & 0 & 1 & 0 & 0 & 0 \\
\hline Cuv & 1 & 1 & 1 & 0 & 1 & 1 & 0 & 0 & 1 & 0 & 0 & 0 & 0 & 0 & 0 & 0 \\
\hline Del & 1 & 1 & 1 & 0 & 1 & 0 & 0 & 1 & 0 & 0 & 0 & 0 & 0 & 0 & 0 & 0 \\
\hline Ech & 1 & 0 & 0 & 0 & 1 & 1 & 0 & 0 & 0 & 0 & 0 & 0 & 0 & 0 & 0 & 0 \\
\hline Gal & 1 & 1 & 1 & 1 & 1 & 0 & 1 & 1 & 1 & 0 & 0 & 0 & 0 & 1 & 0 & 1 \\
\hline Gau & 1 & 1 & 0 & 1 & 1 & 0 & 0 & 1 & 0 & 0 & 0 & 0 & 0 & 0 & 0 & 0 \\
\hline Lel & 1 & 1 & 1 & 0 & 0 & 0 & 0 & 0 & 0 & 0 & 0 & 0 & 0 & 0 & 0 & 0 \\
\hline Men & 1 & 1 & 1 & 1 & 1 & 1 & 1 & 1 & 1 & 1 & 1 & 1 & 1 & 0 & 0 & 0 \\
\hline Meu & 1 & 1 & 0 & 1 & 1 & 1 & 0 & 1 & 0 & 0 & 0 & 0 & 0 & 0 & 0 & 0 \\
\hline Mil & 1 & 1 & 1 & 1 & 1 & 0 & 0 & 0 & 1 & 1 & 0 & 0 & 0 & 0 & 1 & 1 \\
\hline Moy & 1 & 0 & 0 & 1 & 1 & 0 & 0 & 1 & 0 & 1 & 1 & 0 & 0 & 0 & 0 & 0 \\
\hline Pre & 1 & 0 & 0 & 1 & 1 & 1 & 0 & 0 & 0 & 1 & 0 & 0 & 0 & 0 & 0 & 0 \\
\hline
\end{tabular}

Tc: Teladorsagia circumcincta; tco: Trichostrongylus colubriformis; to: Trichuris sp; ov: Oesophagostomum venulosum; tt: Teladorsagia circumcincta morph trifurcata; so: Skrjabinema ovis; oo: Ostertagia ostertagi; hc: Haemonchus contortus; ta: Trichostrongylus axei; nf: Nematodirus filicollis; ns: Nematodirus spatbiger; sp: Strongyloides papillosus; coo : Cooperia sp.; cap: Capillaria sp.; cho: Chabertia ovina.

Table II. - Species of digestive-tract nematodes (0: absent, 1: present) in dairy-goats in autumn from 16 farms in the Centre West region of France.

\begin{tabular}{|c|c|c|c|c|c|c|c|}
\hline Farm & $\begin{array}{c}\text { No. of } \\
\text { goats bought } \\
\text { initially* }\end{array}$ & $\begin{array}{l}\text { No. of farms } \\
\text { from which goats } \\
\text { were originally } \\
\text { sourced* }\end{array}$ & $\begin{array}{l}\text { Goats bought } \\
\text { after the } \\
\text { establishment } \\
\text { of the farm* }\end{array}$ & $\begin{array}{l}\text { How long } \\
\text { the farm has been } \\
\text { in existence } \\
\text { (years)* }^{*}\end{array}$ & $\begin{array}{c}\text { Use } \\
\text { of permanent } \\
\text { pasture }^{* *}\end{array}$ & $\begin{array}{l}\text { Late turn-out } \\
\text { (after May)** }\end{array}$ & $\begin{array}{c}\text { No } \\
\text { treatment }\end{array}$ \\
\hline Aug & 0 & 0 & 1 & 1 & 1 & 1 & 0 \\
\hline Bau & 0 & 0 & 1 & 1 & 1 & 1 & 1 \\
\hline Ber & 1 & 1 & 1 & 0 & 0 & 1 & 1 \\
\hline Bod & 1 & 0 & 1 & 0 & 1 & 1 & 1 \\
\hline Cas & 1 & 1 & 0 & 0 & 0 & 1 & 1 \\
\hline Cuv & 1 & 1 & 1 & 0 & 1 & 1 & 1 \\
\hline Del & 0 & 0 & 1 & 0 & 0 & 1 & 0 \\
\hline Ech & 0 & 0 & 1 & 0 & 1 & 0 & 1 \\
\hline Gal & 1 & 1 & 1 & 0 & 0 & 1 & 1 \\
\hline Gau & 1 & 1 & 1 & 1 & 0 & 1 & 1 \\
\hline Lel & 0 & 1 & 1 & 0 & 1 & 0 & 1 \\
\hline Men & 1 & 1 & 1 & 1 & 0 & 0 & 0 \\
\hline Meu & 0 & 1 & 1 & 0 & 0 & 1 & 1 \\
\hline Mil & 1 & 1 & 1 & 0 & 0 & 1 & 1 \\
\hline Moy & 0 & 1 & 1 & 0 & 0 & 1 & 1 \\
\hline Pre & 0 & 0 & 1 & 0 & 0 & 1 & 1 \\
\hline
\end{tabular}

* quantitative data transformed into binary data (0: lower than average value, 1 : higher than average value).

** Absent: 0 and present: 1 .

Table III. - Characteristics of the goat farms.

to relate parasite communities (binary data) to environmental characteristics (binary transformed data).

The presence/absence of digestive tract-helminths at necropsy in lambs for slaughter from two intensive systems (with and without mixed grazing with cattle) in the tropics are shown in Table IV (individual data). Helminths were identified to genus level. Each cohort of lambs grazed irrigated pasture for four months (from two to six months of age). The five cohorts grazed on the same paddocks within a system. It was expected that lambs grazing with heifers would accumulate cattle species, and therefore accumulate more species over time.

\section{ANALYSES}

Correspondence analysis and UPGMA based on Jaccard distances of the data were carried out using MVSP Software (3.13b, 2001). Hennig86 (Farris, 1988) phylogenetic software was used. The character state (presence/absence of species) found in the ancestral 
type is described as "plesiomorphic", and the derived state that has developed subsequently is described as "apomorphic". Trees were constructed using the principle of parsimony, that requires that ad boc assumptions should be minimised as far as possible: the number of gains/losses/recoveries of species is kept to a minimum. With regard to communities of species, we assumed that when the farm was established, no species was present (ancestral situation) and that progressively species have been gained, but also possibly

\section{Cohorts/ lambs*} Haemonchus Cooperia Trichostrongylus Strongyloides

Oesophagostomum Moniezia

\begin{tabular}{|c|c|c|c|c|c|c|}
\hline \multicolumn{7}{|c|}{ Lambs alone } \\
\hline c11 & 0 & 0 & 1 & 1 & 1 & 1 \\
\hline c11 & 1 & 0 & 0 & 0 & 1 & 0 \\
\hline c12 & 1 & 0 & 0 & 0 & 0 & 0 \\
\hline c13 & 1 & 0 & 0 & 1 & 0 & 1 \\
\hline c14 & 1 & 0 & 0 & 0 & 0 & 0 \\
\hline c15 & 1 & 0 & 0 & 0 & 1 & 0 \\
\hline c21 & 1 & 0 & 0 & 0 & 0 & 0 \\
\hline $\mathrm{c} 22$ & 1 & 0 & 0 & 0 & 1 & 1 \\
\hline c23 & 0 & 1 & 0 & 0 & 0 & 0 \\
\hline c24 & 1 & 0 & 0 & 0 & 1 & 0 \\
\hline $\mathrm{c} 25$ & 1 & 0 & 0 & 0 & 0 & 0 \\
\hline c31 & 1 & 0 & 0 & 0 & 1 & 0 \\
\hline c32 & 1 & 0 & 1 & 0 & 0 & 0 \\
\hline c33 & 1 & 0 & 1 & 0 & 0 & 1 \\
\hline c34 & 1 & 0 & 0 & 0 & 0 & 0 \\
\hline c35 & 1 & 0 & 1 & 0 & 1 & 1 \\
\hline c41 & 1 & 0 & 1 & 1 & 1 & 0 \\
\hline c42 & 1 & 0 & 1 & 1 & 1 & 1 \\
\hline c43 & 1 & 0 & 0 & 0 & 0 & 1 \\
\hline c44 & 1 & 0 & 1 & 0 & 1 & 0 \\
\hline c45 & 1 & 0 & 0 & 0 & 0 & 0 \\
\hline c51 & 1 & 0 & 1 & 1 & 0 & 0 \\
\hline c5 52 & 1 & 0 & 1 & 0 & 1 & 1 \\
\hline c53 & 1 & 0 & 0 & 0 & 1 & 0 \\
\hline c54 & 1 & 0 & 0 & 1 & 1 & 1 \\
\hline c55 & 1 & 0 & 1 & 0 & 0 & 1 \\
\hline
\end{tabular}

\begin{tabular}{|c|c|c|c|c|c|c|}
\hline \multicolumn{7}{|c|}{ Lambs plus heifers } \\
\hline $\mathrm{c} 11$ & 1 & 1 & 1 & 1 & 1 & 0 \\
\hline c12 & 1 & 0 & 0 & 0 & 1 & 0 \\
\hline $\mathrm{c} 13$ & 1 & 1 & 0 & 1 & 1 & 1 \\
\hline c14 & 1 & 1 & 1 & 1 & 0 & 1 \\
\hline $\mathrm{c} 15$ & 1 & 0 & 0 & 0 & 1 & 0 \\
\hline $\mathrm{c} 21$ & 1 & 1 & 0 & 0 & 0 & 0 \\
\hline $\mathrm{c} 22$ & 1 & 0 & 0 & 1 & 1 & 0 \\
\hline $\mathrm{c} 23$ & 1 & 0 & 0 & 0 & 0 & 0 \\
\hline $\mathrm{c} 24$ & 1 & 1 & 0 & 0 & 0 & 0 \\
\hline $\mathrm{c} 25$ & 1 & 1 & 0 & 0 & 1 & 0 \\
\hline c31 & 1 & 1 & 1 & 1 & 0 & 0 \\
\hline c32 & 1 & 1 & 0 & 0 & 1 & 1 \\
\hline c33 & 1 & 1 & 0 & 0 & 1 & 1 \\
\hline c34 & 1 & 1 & 1 & 0 & 0 & 0 \\
\hline c35 & 1 & 0 & 0 & 0 & 1 & 0 \\
\hline c41 & 1 & 1 & 1 & 0 & 1 & 1 \\
\hline c42 & 1 & 1 & 0 & 1 & 1 & 1 \\
\hline c43 & 1 & 1 & 0 & 1 & 1 & 0 \\
\hline c44 & 1 & 1 & 0 & 0 & 1 & 1 \\
\hline c45 & 1 & 1 & 0 & 1 & 1 & 0 \\
\hline c51 & 1 & 1 & 1 & 0 & 0 & 0 \\
\hline $\mathrm{c} 52$ & 1 & 1 & 0 & 0 & 1 & 0 \\
\hline c53 & 1 & 1 & 0 & 0 & 0 & 0 \\
\hline c54 & 1 & 1 & 0 & 0 & 1 & 0 \\
\hline$c 55$ & 1 & 1 & 1 & 0 & 0 & 0 \\
\hline
\end{tabular}

* C11: means cohort 1 and lamb 1 etc.

Table IV. - Helminth genera in cohorts of lambs grazed alone or with heifers in the French West Indies. 
lost. A full set of informations about how to use the program for community studies is available (Cabaret, 2003). The $h^{*}$ command constructs a single cladogram by a single pass through the data, and then applies branch-swapping to that tree. The cladograms in shape of a tree-like graphic were constructed using Tree-gardener (1997). We use the term of "cladogram", as our analysis specified the relative degree of phylogenetic relationship of the analysed farms, but did not attempt to specifying direct ancestor-descendant relationships (like a pedigree) as in phylogenetic trees (Kitching et al., 1998). The length of the cladogram (L), is the total number of character state changes (the presence or absence of species) necessary to support the relationship of the farms in the tree: the shortest cladogram is the most parcimonious. The overall consistency (CI) indicates the degree of fit between the data and the constructed cladogram; $100 \%$ consistency implies that the fit is perfect. The retention index (RI) is a measure of the degree $(\%)$ of similarity in the presence of the species that can be interpreted as synapomorphy (presence of a species that unites several farms on the cladogram): higher values are expected in informative cladograms (Lipscomb, 1994). The phylogenetic ana- lysis detects groups of farms that are homogeneous in terms of species assemblage. The environment variables are determined within each of these homogeneous groups, and the degree of correspondence between homogeneous groups (HG) and the environment can be tested using Fisher exact probability test (Siegel, 1956). This makes it possible, for example, to test whether a four- farm assemblage in which an environmental variable occurs in three of the farms is statistically significant or not, compared to the frequency of the environmental variable among the set including all the farms.

\section{RESULTS}

INTERPRETING TREES IN POLYTHETIC DATA (Fig. 1)

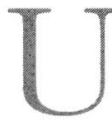

PGMA and correspondence analysis identified similar homogeneous groups, HG1, HG2' and a third group (m, n, o, p or and n, l, o, p, respectively). Inertia The high inertia values of the first two axes (88\% variance) in the correspondence analysis indicated that the arrangement into three groups

\section{A - Phylogenetic analysis}

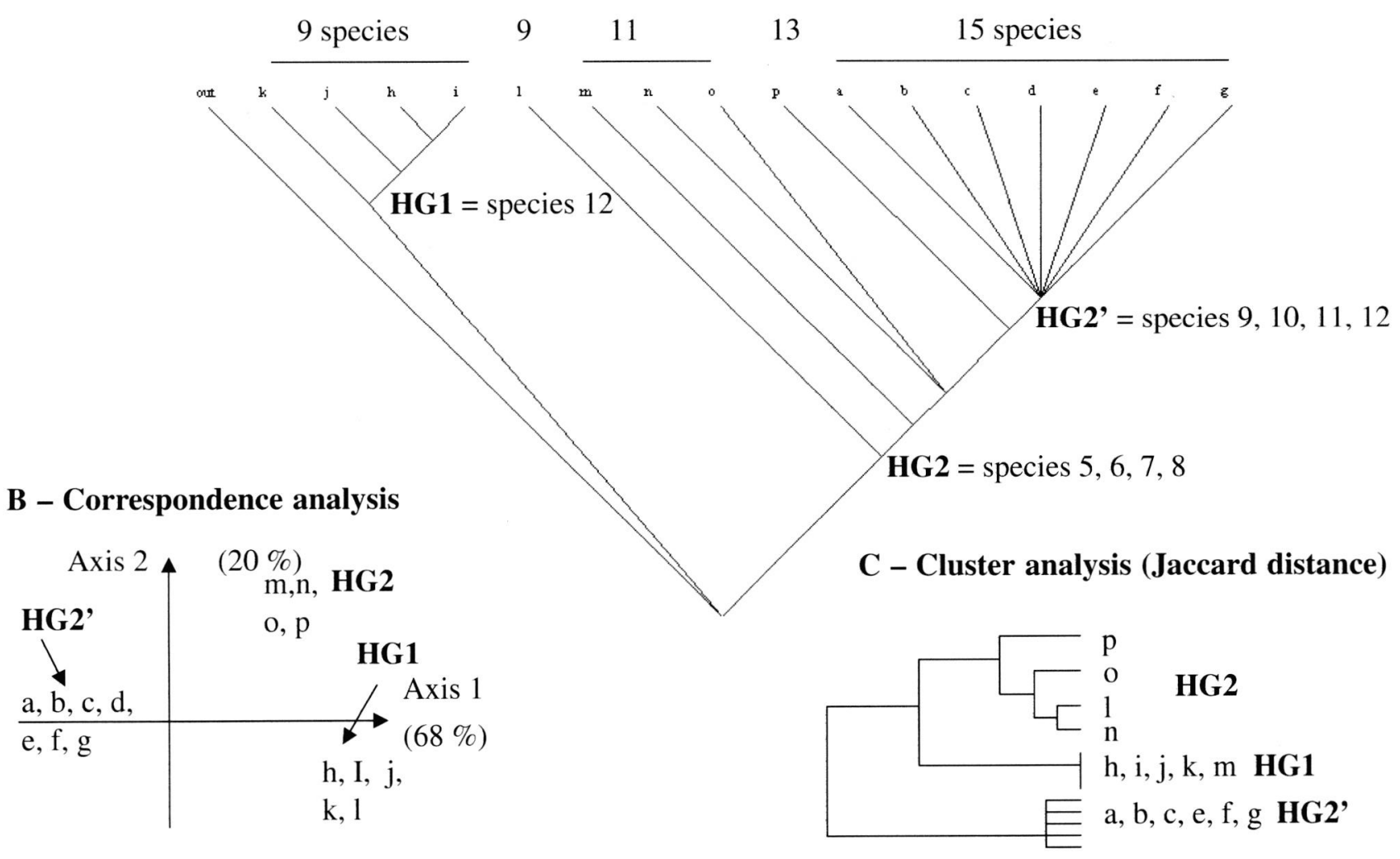

Fig. 1. - Compared analyses (phylogenetic-A, correspondence-B and cluster analyses-C) of imaginary parasite community data. Three homogeneous parasite community groups (HG1, HG2 and HG2') were identified in all three types of analyses. Only HG1 is the same in the all three analyses. Out corresponds to the outgroup (no community). 
was reliable. The Hennig cladogram $(\mathrm{L}=33, \mathrm{CI}=48$ and $\mathrm{RI}=71$ ) using the $\mathrm{h}^{*}$ command was supported by the use of mhennig* command (the same as $\mathrm{h}^{*}$ but including the farms' taxa in a different sequence each time, and then applied branch swapping to each of the trees, retaining just one tree for each initial tree). The bb command, which retains up to 100 of the shortest trees, produced only seven cladograms instead of the six yielded by mhennig*. The consensus cladogram (Nelson procedure) gave a similar result to $h^{*}$, but with a slightly longer tree (38) and lower $\mathrm{ci}=42$ and $\mathrm{ri}=$ 62). For our type of limited data there was no real advantage in exploring the construction of the cladograms further than with the $\mathrm{h}^{*}$ command, and in the examples that follow we only used this command. From the cladogram in Figure 1, we can propose the following history: an initial homogeneous group of farms (HG1) had acquired nine species, among which species 12 is particularly characteristic; a second loose group (HG2) was based on the progressive acquisition of further species $(5,6,7$ and 8), and a third group (Hg1') within the HG1 group, was the group with the most species (15), and was characterised by certain species $(9,10,11$ and 12). The characteristics of the cladograms were tested on imaginary matrices 15 farms $\times$
14 species (data not shown) with: $i$ ) a diagonal of zero values (absence of species) and other values with species present (fully polythetic matrix), $i$ ) a diagonal of 1 (presence of species) with all other values set to zero. The first situation represents the fact that all the farms have a large number of species, although not the full set of species, and that they are very similar. The second extreme situation indicates that each farm has only one species, and that it is a different species for each farm, so that the farms are extremely different. The lengths are 26 and 14, with CI values of 53 and 100 , and RI values of 42 and 100 respectively. The farm by species matrix we analysed extensively in detail was much closer to the first situation, based on length, L, CI and RI.

\section{ESTABLISHING GROUPS OF DAIRY-GOAT FARMS WITH A HOMOGENEOUS ASSEMBLAGE OF SPECIES AT ONE PERIOD (Fig. 2, Tables II and III)}

The correspondence analysis (not shown) indicated a continuum of farms along a gradient from the presence of Nematodirus spp. and Strongyloides (Meu and Men) to the presence of Cooperia, Capillaria, and Oesophagostomum (Gal \& Mil). The following homogeneous farm groups were identified using UPGMA: $i$ ) Aug, Bau,

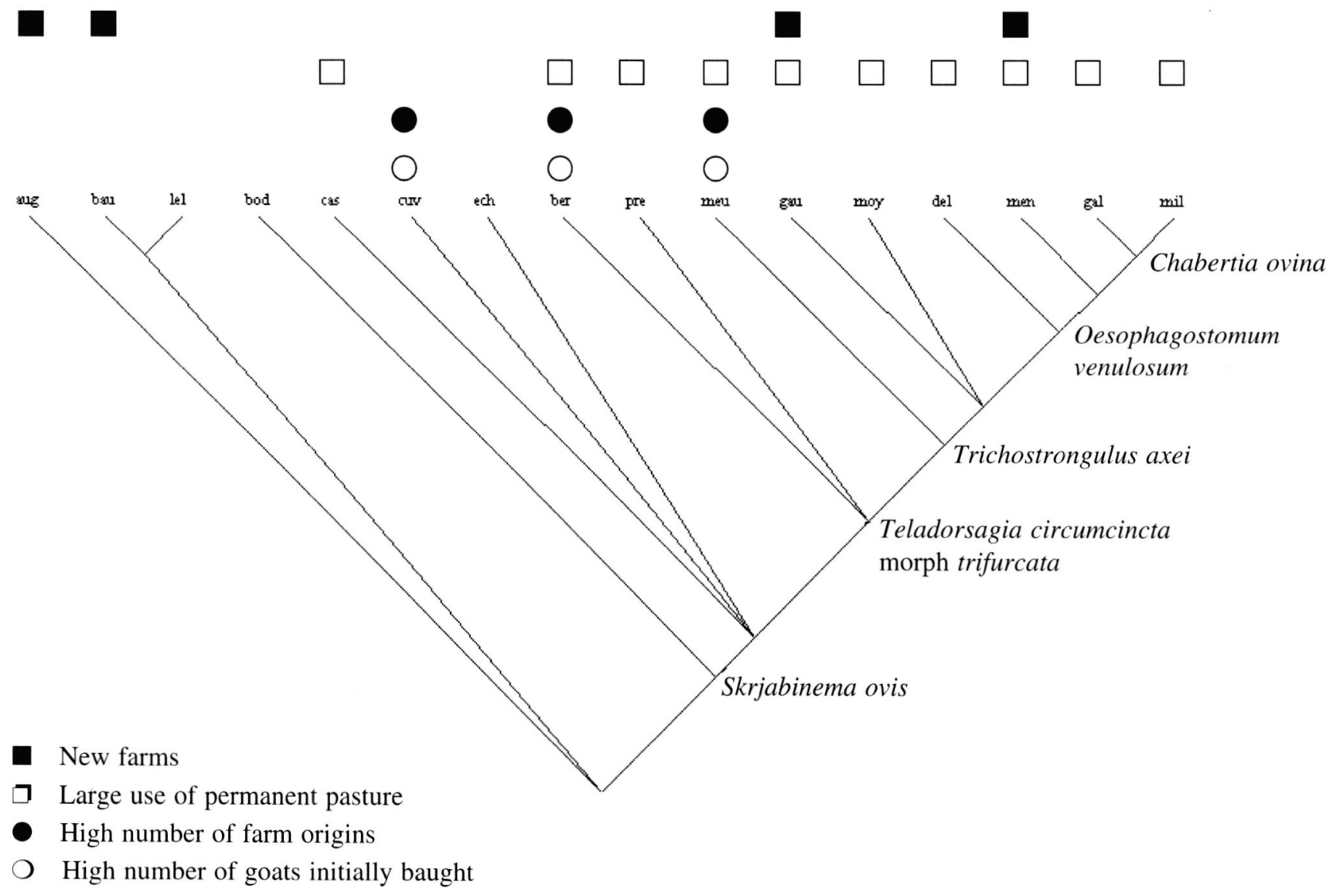

Fig. 2. - Cladogram of the trichostrongyle nematode communities in 16 dairy goats farms in autumn in relation to farming history. 
Lambs grazing alone $($ Length $=15 ; \mathrm{CI}=42 ; \mathrm{RI}=75)$

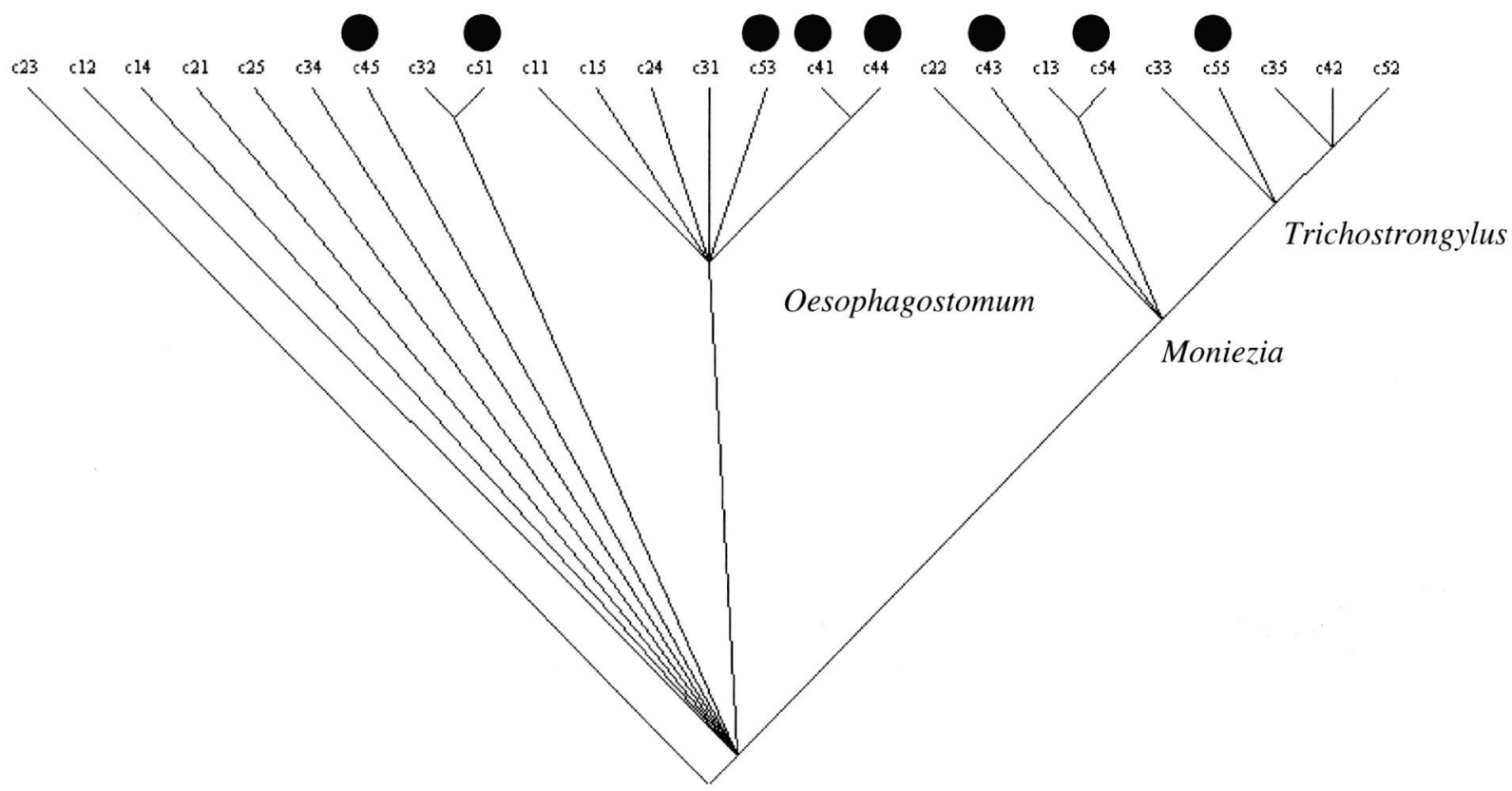

Lambs grazing with cattle $($ Length $=13 ; \mathrm{CI}=46 ; \mathrm{RI}=78)$

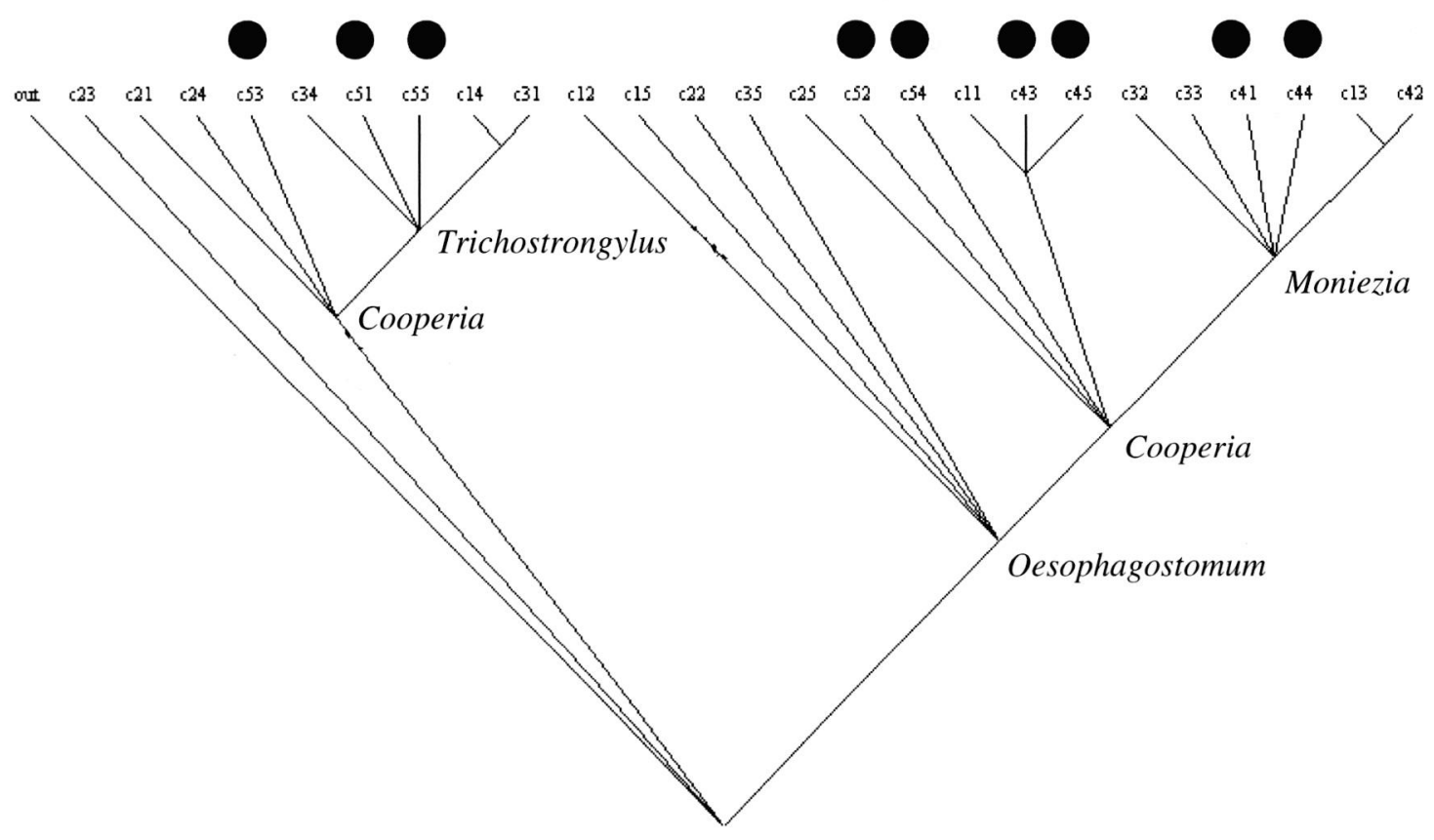

Ultimate cohorts 4 and 5

Fig 3. - Cladogram of helminth communities in the digestive-tracts of cohorts of lambs grazed alone or with cattle. Out corresponds to the outgroup (no community). Length, consistency index CI and retention index RI are characteristics of the cladogram. 
Bod, Lel, ii) a large group that could be split into two: a) Ech, Moy, Pre and b) Ber, Cas, Cuv, Del, Gal, Gau, Men, Meu, Mil. The cladogram (Fig. 2) did not reveal very distinct groups, and the same order was not obtained using UPGMA (see Ech, Moy, Pre, for example) and correspondence analysis. The number of species on the farms ranged from low (on the left) to high (on the right of the cladogram). Farm management was located by reference abbreviations (first three letters of farm owner's name) to the cladogram and Fisher exact test was performed. The heavy use of permanent pastures was closely linked to the number of species ( $p=0.0009$ ), and possibly to the number of farms from which goats had been bought when the farm was established ( $p=0.14$ ). The number of goats and the time since the farm was established were not significantly related to species richness $(\mathrm{p}=0.23$ and $\mathrm{p}=0.21$, respectively). The farm data can be related to the assemblage of species. The assemblages progressively incorporated progressively $S$. ovis, $T$. circumcincta morph trifurcata, T. axei, O. venulosum, and C. ovina. The gain of the last four taxa was linked to the use of natural pasture.

\section{EVOLUTION OF THE HELMINTH COMMUNITY IN SEVERAL COHORTS OF LAMBS GRAZED UNDER TWO SYSTEMS (Fig. 3, Table IV)}

The correspondence analyses did not discriminate well between the cohorts in the two systems (data not shown). UPGMA distinguished between the early 1, 2 and 3 and late 4 and 5 cohorts in the lambs-only system (data not shown). The construction of the communities over time was different in the two systems using phylogenetic analysis. The lambs grazing alone had two types of communities, one including Oesophagostomum and the other Moniezia. These two developments were both seen in the last two cohorts ( 4 and 5), but were not significant $(p=0.23$ ). Three seasons were investigated (data not shown), and the first season and the latest cohort were associated with Moniezia and Trichostrongylus $(\mathrm{p}=0.06)$. No seasonal influence was recorded in the lambs grazed alongside cattle. The communities including Cooperia and Moniezia were significantly associated with the later cohorts $(\mathrm{p}=0.05)$. Communities including Cooperia and Trichostrongylus but consisting of fewer species were also associated with the laster cohorts $(p=0.16)$.

\section{DISCUSSION}

$\mathrm{P}$ hylogenetic analysis provided more information than the classical analysis of binary data. This concurred with the findings of Lambshead and Paterson (1994) and Bellon-Santini et al. (1994). Our binary data findings also match previous analyses based on quantitative data in dairy goats: the major importance of the area of permanent pastures for goats for the number and diversity of parasitic species is clearly demonstrated (Cabaret \& Gasnier, 1994, on the same data set; Gasnier et al., 1997 on a larger set of data; Silvestre et al., 2000 in another region).This has made it possible to describe the communities involved, which was not clearly done in previous analyses. The species gained in the communities were the rarer ones (morph trifurcata, C. ovina and O. venulosum) or the unevenly distributed species ( $T$. axei). The lambs data had previously been analysed in terms of species diversity and species richness, and it was found that these two indices were higher in the lambs grazed with cattle (Giudici et al., 1999). The influence of cohort was demonstrated on Haemonchus (which declined with time) and Trichostrongylus (which increased in the last cohort). The phylogenetic analysis demonstrated the role of Cooperia (a nematode usually found in cattle) in the communities in the mixed grazing system. Trichostrongylus was found in the last cohorts as had previously been found from quantitative data. In both examples, the phylogenetic analysis was very effective in finding assemblages of species in terms of the main environmental factors (area of permanent pasture or mixed grazing and the change over time). This could mean that the historical dimension plays a major role in the construction of the helminth assemblage, and that analyses that rely on a historical reconstruction (i.e. the progressive gain of species over time) are more suitable than those based solely on similarity. Nel \& Nel (1998) commented forcefully on the difference between cladistics (inheritance with modification of character) and use of Wagner parsimony (a tool to define the derived state of characters, e.g. species). They indicated that a set of sites (or farms in our example) could not be considered to be phylogenetic clades because: i) species exchange is always possible between the localities, ii) species, unlike characters, exists independently of the sites where they live, $i i i$ ) there is no common history of the sites, as there is no phylogenetic linkages between sites and no common ancestral site. They also criticised the use of the outgoup without species (Lambshead \& Paterson, 1994; BellonSantini et al., 1994, and and the present analysis) and preferred non-hypothetical outgroups. These criticisms are justified for natural sites studies (Brooks, 1985 for example), but are less pertinent in agronomical situations, when part of the real history is known, and when zero-species outgroups are the rule for any new farm. The very limited introductions of infected hosts after the establishment of the farm give some value to the species as a character. The situation in farms with a known history made the cladistic method more acceptable than under natural conditions. 
The method we propose was based on two examples and it would be interesting to apply it to a wider range of situations. The analysis of an imaginary data set, including polythetic groups (each farm has a large number of species, and each species is found on a large number of farms), much of it corresponding to real data in parasitic faunas, shows that the method can be applied to most sets of parasitic data. We restricted our investigation to communities and environmental conditions in agronomic conditions. Wanntorp et al. (1990) have described examples under natural environmental conditions, which indicates that phylogenetic methods are a useful tool for the ecologists. One main problem is the lack of statistical power when relating communities and environmental factors, as most data sets contain only a limited number of cases (farms or sites). Hennig86 is only one of the numerous phylogeny programs available, and although it meets most of the requirements for establishing cladograms based on parsimony (Platnick, 1989), it only uses the Wagner algorithm, whereas other programs also propose the Camin-Sokal (allowing convergence) or Dollo (allowing reversions) methods (Darlu \& Tassy, 1993). This limitation is not important when the characters are binary, which is often the case in community analysis. As it is, Hennig86 provides a useful tool for understanding community structures of up to 999 species and 189 sites/farms.

\section{ACKNOWLEDGEMENTS}

1 The present method originated from discussions with colleagues (L. Gruner, P. Delattre, T. Hallas and B. Gudleifsson) and has been funded within the context of an European Program (FAIR J-CT98 7023: Role of environmental and host factors on the horizontal and vertical transmission of scrapie in naturally infected sheep flocks). The use and limitations of the method for relating farm management and parasite community was discussed with colleagues (M. Benoit and H. Hoste) during a GIS Massif Central meeting in 2003 on organic farming.

\section{REFERENCES}

BeCKner M. The biological way of thought. Columbia University Press, 1959, New York.

Bellan-Santini D., Dauvin J.C. \& Bellan G. Analyse de données en écologie benthique : utilisation de la méthode de l'analyse de parcimonie. Oceanologica Acta, 1994, 17, 331-340.

BROOKS D.R. Historical ecology: a new approach to studying the evolution of ecological associations. Annals of Mo. Botanical Garden, 1985, 72, 660-580.
Cabaret J. Practical tips for using Hennig86 in parasite community studies. 2003. http://www.tours.inra.fr/sfpar/ stat.htm

Cabaret J. \& Gasnier N. Farm history and breeding management influences on the intensity and specific diversity of nematodes infection of dairy goats. Veterinary Parasitology, 1994, 53, 219-232.

CABaret J. \& Schmidt E.E. Species diversity of digestive-tract nematode communities of domestic ruminants: multivariate versus univariate estimations. Parasitology Research, 2001, 87, 311-316.

Darlu P. \& Tassy P. Reconstruction phylogénétique. Concepts et méthodes. Masson, 1993, Paris,. 245 p.

FARRIS J.S. Hennig 86: a PC Dos program for phylogenetic analysis. Cladistics, 1989, 5, 163.

Gasnier N., Cabaret J., Chartier C. \& Reche B. Species diversity in gastrointestinal nematode communities of dairtygoats: species-are and species-climate relationships. Veterinary Research, 1997, 28, 55-64.

Giudici C., Aumont G., Mahieu M., Saulai M. \& Cabaret J. Changes in gastrointestinal helminths species diversity in lambs under mixed grazing on irrigated pastures in the tropics (French West Indies). Veterinary research, 1999, 30, 573-581.

Kitching I.J., Forey P.L., Humphries J. \& Williams D.M. Cladistics. The theory and practice of parsimony analyses. Oxford University Pres, Oxford, 1998,. 228 p.

Lambshead P.J.D. \& Paterson G.L.G. Ecological cladistics - An investigation of numerical cladistics as a method for analysing ecological data. Journal of Natural History, 1986, 20, 895-909.

Lipscomb D. Cladistic analysis using Hennig86. 1994. G. Washington University, Washington, 122 p. http://www.gwu.edu/ $\sim$ clade/faculty/lipscomb/web.pdf

MVSP PLus. Multivariate Statistical package, Version3.1. User's Manual. 2001, Kovach Computing services, Pentraeth, Wales, $137 \mathrm{p}$.

NeL A. \& Nel J. An investigation into the aplication of the Wagner parsimony method in synecology. Biological Journal of the Linnean Society, 1998, 63, 165-189.

PEET R.K. The measurement of species diversity. Annual review of Ecology and Systematics, 1975, 5, 285-307.

PlatNICK N.I. An empirical comparison of microcomputer parsimony programs, II Cladistics, 1989, 5, 145-161.

RoutleDGE R.D. Diversity indices: which ones are admissible. Journal of Theoretical Biology, 1979, 76, 503-515.

SIEGEL S. Nonparametric statistics for the behavioral sciences. McGraw-Hill, 1956, New York, 312 p.

Silvestre A., Chartier C., Sauvé C. \& Cabaret J. Relationship between helminth species diversity, intensity of infection and breeding management in dairy goats. Veterinary Parasitology, 2000, 94, 91-105.

Tree Gardener 2.2 (Tiago Courrol Ramos) Manual, 1997. htpp://www.tours.inra.fr/sfpar/stat.htm

Wanntorp H.E., Brooks D.R., Nilsson T., Nylin S., RonQUist F., STEARNS S.C. \& Wedell N. Phylogenetic approaches in ecology. Oikos, 1990, 57, 119-132.

WhitTaker R.H. Communities and ecosystems. Mac Millan, New York, 1975.

Reçu le 3 juin 2003 Accepté le 15 septembre 2003 